\title{
Deactivation of sulfonated hydrothermal carbons in the presence of alcohols: evidences for sulfonic esters formation
}

José M. Fraile, ${ }^{a *}$ Enrique García-Bordejé, ${ }^{b}$ Laura Roldán ${ }^{a}$

${ }^{a}$ Instituto de Síntesis Química y Catálisis Homogénea (ISQCH), Facultad de Ciencias, C.S.I.C. - Universidad de Zaragoza, E-50009 Zaragoza, Spain. E-mail: jmfraile@unizar.es ${ }^{b}$ Instituto de Carboquimica (ICB-CSIC), Miguel Luesma Castán 4, E-50018 Zaragoza, Spain

\begin{abstract}
Sulfonated hydrothermal carbons show high activity for esterification of palmitic acid with alcohols. However, the catalyst is significantly deactivated upon recovery. Leaching of sulfonated species does not account for this deactivation, which is observed even by pretreatment only with the alcohol under reflux. Solid state NMR shows the presence of chemically bound alkyl groups coming from the alcohol, clearly different from strongly physisorbed species obtained by pretreatment at room temperature. The formation of sulfonate esters accounts for the deactivation behavior in reactions taking place in alcohols as solvents, mainly with methanol due to its higher reactivity.
\end{abstract}

Keywords: sulfonated hydrothermal carbons; esterification; deactivation; acid catalysts 


\section{Introduction}

The use of catalytic processes seems to be one of the most important Green Chemistry principles with regard to chemical production [1]. Mineral acids are among the most ubiquitous catalysts in industry but their corrosion and toxicity problems have prompted to the search for recoverable and reusable heterogeneous acid catalysts $[2,3]$. Fatty acid esters are present in a wide variety of daily used products, such as fuels, pharmaceuticals, cosmetics or foodstuffs. When the use of mixtures is allowed, they can be obtained by direct transesterification of fats and oils using either acid [4] or basic [5] catalysts. On the contrary, when the final application requires the use of a pure fatty acid ester, or free fatty acids are present in large amount in the triglycerides mixtures, the synthetic method of choice is the esterification of the fatty acid using an acid catalyst [6]. Among the huge amount of different solid acids, sulfonated carbons are emerging as an interesting alternative $[7,8]$ due to the special features of those materials, including the sustainability issues in the case of carbons prepared from feedstock biomass instead of fossil fuels. In fact, sulfonated carbons obtained by partial carbonisation of glucose or cellulose have been used as catalysts for esterification reactions [9-13], as well as monoliths prepared by one-pot synthesis in the presence of $p$-toluenesulfonic acid [14]. Sulfonated mesoporous carbon was obtained by replication of SBA-15 pores through carbonisation of sucrose, leading to highly active solids [15]. Hydrothermal carbonisation (HTC) [16] is an attractive mild method of preparation of carbons with properties different from those prepared by more conventional methods. The accessible external surface densely functionalised with polar groups, such as carboxylic, hydroxyl or quinine [17], confers them high hydrophilicity and susceptibility to chemical modification. Sulfonated hydrothermal carbons, either prepared in two steps [18] or in one-pot synthetic method 
[19], have been also used as acid catalysts for esterification reactions. Furthermore, hydrothermal carbon synthesis is a very versatile method to prepare materials with different porous structures [20-24] and shapes, such as hollow capsules [25-27], nanowires [28] or nanotubes [29]. Recently, it has been demonstrated by our group that HT carbon films can be also coated on a structured macroscopic support such as graphite felt [30].

Deactivation is a general problem in heterogeneous catalysis but it is a rather complicated phenomenon, related to coke formation, pore filling, structure modification, and a large variety of processes that depend on the type of catalyst and the catalytic reaction $[31,32]$. This is also the case of acid catalysts used in esterification reactions. In the case of sulfonated carbons, deactivation has been attributed to leaching of soluble polycyclic aromatics with sulfonic groups [14,33], simple physical loss of catalyst [15], or hydrolysis of sulfonic groups [34]. Other acid catalysts have also shown a similar behaviour with respect to stability in esterification reactions, that have been explained by leaching problems in sulfated zirconia [35], hydrocarbon accumulation in SAC-13 [36] and organosulfonic silica [37], and several reasons, including leaching of sulfonic species, water and glycerol adsorption, and even reaction with methanol in the case of sulfonic-acid modified SBA-15 [38,39].

In this manuscript the deactivation of sulfonated hydrothermal carbon in esterification reactions is studied, with evidences for different mechanisms, including the formation of sulfonic esters with the corresponding alcohol. The knowledge of these deactivation mechanisms may be the basis for designing catalytic processes which minimise this deactivation. 


\section{Experimental}

\subsection{Hydrothermal synthesis}

An aqueous solution of glucose $(25 \mathrm{ml}, 1 \mathrm{M})$ was placed in a Teflon-lined autoclave and the hydrothermal synthesis was carried out under autogenous pressure at $195{ }^{\circ} \mathrm{C}$ for 19 h. After the synthesis, the autoclave was cooled down in a water bath at room temperature. The obtained material was washed thoroughly with distilled water and ethanol, and finally dried overnight in an oven at $105^{\circ} \mathrm{C}$.

The resulting material was then treated with concentrated (>96\%) sulfuric acid (20 $\mathrm{mL} \mathrm{H}_{2} \mathrm{SO}_{4} / \mathrm{g}$ solid) at $150^{\circ} \mathrm{C}$ under argon atmosphere for $16 \mathrm{~h}$. The sulfonated sample was then washed thoroughly with hot distilled water and dried overnight at $105^{\circ} \mathrm{C}$.

\subsection{Characterization}

Surface areas were determined by $\mathrm{N}_{2}$ adsorption (BET) using a Micromeritics ASAP 2020 apparatus. Typically, a $0.2 \mathrm{~g}$ of solid was used for measurements. Prior to $\mathrm{N}_{2}$ adsorption, the sample was outgassed for $4 \mathrm{~h}$ at $423 \mathrm{~K}$. C,H,S analyses were carried out by combustion in a ThermoFlash 1112 elemental analyzer equipped with a TCD detector. For sample preparation, about $3 \mathrm{mg}$ of sample are mixed with $\mathrm{V}_{2} \mathrm{O}_{5}$ in a crucible. Oxygen analysis was done by direct assay which involves pyrolysis of the sample.

SEM analysis was carried out with a microscope SEM EDX Hitachi S-3400 N with variable pressure up to $270 \mathrm{~Pa}$ and with an analyzer EDX Röntec XFlash de $\mathrm{Si}(\mathrm{Li})$. The samples were sputtered with gold previously to measurements. The images were obtained from the secondary electron signal.

For infrared analysis, samples were first ground in an agate mortar to produce fine powder that was mixed with pure $\mathrm{KBr}$ (Merck for spectroscopy) using a weight ratio of 1:20. About $30 \mathrm{mg}$ of the mixture was used to prepare each pellet by compressing at 10 
tonnes $\mathrm{cm}^{-2}$ using a hydraulic press. Infrared spectra were recorded with a Nicolet Avatar 360 spectrometer over the wavenumber range of $4000-400 \mathrm{~cm}^{-1}$ with 300 scans.

NMR spectra were recorded in a Bruker Avance III WB400 spectrometer with 4 $\mathrm{mm}$ zirconia rotors spun at magic angle in $\mathrm{N}_{2}$ at $10 \mathrm{kHz} .{ }^{1} \mathrm{H}$ spectra (16 scans) were acquired using a single pulse excitation with $\pi / 2$ pulse length of $3 \mu \mathrm{s} .{ }^{1} \mathrm{H}_{-}{ }^{13} \mathrm{C} \mathrm{CP}$ spectra (10000 scans) were measured using a ${ }^{1} \mathrm{H} \pi / 2$ pulse length of $2.45 \mu \mathrm{s}$, with a contact time of $2 \mathrm{~ms}$, and spinal64 proton decoupling sequence of $4.6 \mu$ s pulse length. Direct polarization ${ }^{13} \mathrm{C}\left\{{ }^{1} \mathrm{H}\right\}$ spectra (60 scans) were measured using a ${ }^{13} \mathrm{C} \pi / 2$ pulse length of $4.5 \mu \mathrm{s}$, and continuous wave proton decoupling of $4.5 \mu$ s pulse length.

\subsection{Catalytic tests}

$7.5 \mathrm{mmol}$ of palmitic acid (1.92 g), $75.0 \mathrm{mmol}$ of alcohol (3.04 $\mathrm{ml}$ of methanol, 4.38 $\mathrm{ml}$ of ethanol or $5.78 \mathrm{ml}$ of isopropanol), $100 \mathrm{mg}$ of catalyst and $2.1 \mathrm{mmol}$ of 1 methylnaphthalene $(0.30 \mathrm{~g})$ as internal standard were stirred $(\approx 1000 \mathrm{rpm})$ in a round flask immersed into a silicone bath at $85^{\circ} \mathrm{C}$. Reaction was monitored by gas chromatography (HP-5890-II). The catalyst was filtered, washed with $\mathrm{CH}_{2} \mathrm{Cl}_{2}$, dried under vacuum, and reused under the same conditions.

\subsection{Deactivation tests}

The catalyst $(150 \mathrm{mg})$ was stirred under reflux in the corresponding solvent $(40 \mathrm{ml})$

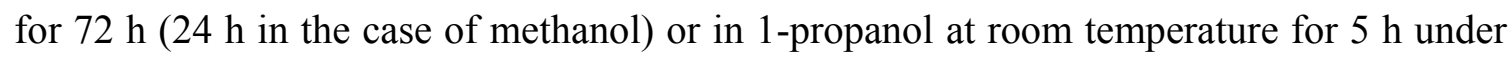
argon atmosphere. The solid was filtered at the same temperature and dried under vacuum at $105^{\circ} \mathrm{C}$ in the case of treatment under reflux or at room temperature in the case of treatment without heating. The solid was used in esterification of palmitic acid with methanol under the standard conditions. In some cases the activity of the extract was tested 
by evaporating the extraction solvent (in case it was different from methanol), addition of methanol (if required), palmitic acid and internal standard and heating at $85^{\circ} \mathrm{C}$.

\section{Results and Discussion}

\subsection{Preparation and characterization of the sulfonated hydrothermal carbon}

Hydrothermal carbons (HC) were prepared from aqueous solutions of glucose, using different concentrations $(0.55$ and $1 \mathrm{M})$, synthesis temperatures $\left(180\right.$ and $\left.195^{\circ} \mathrm{C}\right)$ and times $(8,19$ and $43 \mathrm{~h})$. At $180^{\circ} \mathrm{C}$ or after $8 \mathrm{~h}$, the $\mathrm{HC}$ yield was very low. Thus the standard method included the use of glucose as starting material at $1 \mathrm{M}$ concentration to maximize the productivity per volume and hydrothermal synthesis at $195^{\circ} \mathrm{C}$ for $19 \mathrm{~h}$. The only effect of longer synthesis times was an increase in particle size, with little effect on composition or textural properties (surface area and porosity). Sulfonation was carried out by treatment with concentrated sulfuric acid at $150^{\circ} \mathrm{C}$ for $16 \mathrm{~h}$ under inert atmosphere, leading to sulfonated hydrothermal carbons $\left(\mathrm{HC}-\mathrm{SO}_{3} \mathrm{H}\right)$.

Hydrothermal carbon (HC) was obtained in the form of nanospheres $(300-400 \mathrm{~nm}$ diameter, Figure 1), slightly smaller than those reported in analogous materials [40]. Longer synthesis times led to larger spheres, around $1.5 \mu \mathrm{m}$ diameter after $43 \mathrm{~h}$ synthesis (not shown). Apparently the nanospheres were not modified by the sulfonation process. Surface area, determined by nitrogen adsorption isotherms, is always low, around $7 \mathrm{~m}^{2} \mathrm{~g}^{-1}$ for $\mathrm{HC}$, slightly higher than values reported in the literature $[18,40]$, in agreement with the smaller particle size. The microporous volume is also very low, around $0.2 \mu \mathrm{g} \mathrm{g}^{-1}$.

Hydrothermal synthesis from carbohydrates leads to carbonaceous materials with relatively high oxygen content $[40](\mathrm{O} / \mathrm{C}$ ratio $=0.304$, Table 1$)$. Sulfonation produces a 
significant increase in the oxygen content of the material $[18](\mathrm{O} / \mathrm{C}$ ratio $=0.528$, Table 1$)$, probably due to oxidation processes taking place besides sulfonation with sulfuric acid. The sulfur content corresponds to a functionalization of $0.55 \mathrm{mmol} \mathrm{g}^{-1}$.

The chemical nature of the carbon was studied by IR and NMR spectroscopies. The most prominent IR bands (Figure 2) were the very broad one $\left(3600-3000 \mathrm{~cm}^{-1}\right.$ ) corresponding the stretching of hydroxyl groups, that of aliphatic $\mathrm{C}-\mathrm{H}$ at around $2900 \mathrm{~cm}^{-1}$, the band of carbonyl groups at $1710 \mathrm{~cm}^{-1}$, and bands attributable to skeletal $\mathrm{C}=\mathrm{C}$ vibrations in the range of $1650-1400 \mathrm{~cm}^{-1}$. Sulfonation modifies the spectrum, but sulfonic groups are not easily identifiable in the IR spectrum.

Due to the quite large hydrogen content (Table 1), hydrothermal carbons can be analyzed by NMR spectra in solid state using the cross-polarization technique $\left({ }^{13} \mathrm{C}-\mathrm{CP}\right.$ MAS-NMR). The spectra of the as-prepared samples (Figure 3) are in good agreement with the data reported in the literature $[40,41]$. Three distinct zones can be observed in the spectrum. The $0-60 \mathrm{ppm}$ zone is typical for $\mathrm{sp}^{3}$ (aliphatic) carbons; the $100-160 \mathrm{ppm}$ zone corresponds to $\mathrm{sp}^{2}$ (aromatic and olefinic) carbons, and it can be divided in two wide bands, one in the normal interval of 100-140 ppm and another one at 140-160 ppm, typical for O$\mathrm{C}=\mathrm{C}$; finally the peak at $200 \mathrm{ppm}$ can be attributed to carbonyl groups. The high intensity of the aliphatic band demonstrates de presence of incompletely carbonized material, in agreement with the rather high oxygen and hydrogen contents. The aromatic groups in the hydrothermal carbon are mainly furans, as demonstrated by the band at 140-160 ppm, either with directly bound furan rings (bifuryl moieties) or with aliphatic or carbonyl spacers [40,41]. Simple sulfonation should not significantly modify this spectrum but it is not the case as shown in Figure 3. The increasing importance of the aromatic bands and the almost disappearance of the band for aliphatics demonstrate the existence of side reactions 
in addition to the simple sulfonation. Some of those side reactions may be the oxidation of hydroxyl groups, the oxidation of benzylic methylene groups in $\alpha$ position to furans, the cross-linking and cyclization reactions of the polyfuran chains due to alkylation with hydroxyl or carbonyl groups, and the aromatization of partially saturated furan or benzene rings. In general all those types of reactions can be explained by either the strong acidic character of the sulfonation medium or the oxidant behavior of sulfuric acid, and they would account for the decrease in hydrogen content, the increase in oxygen content (Table 1), as well as the disappearance of the aliphatic bands in NMR. The lack of bands corresponding to carbonyl groups seems to indicate that they participate in the side reactions, for example alkylation of aromatics, and hence the high oxygen content must be due to phenol and ether groups, in addition to the furan rings.

\subsection{Catalytic activity}

Catalytic activity of the sulfonated carbons was tested in the esterification of palmitic acid with methanol (Figure 4). $\mathrm{HC}-\mathrm{SO}_{3} \mathrm{H}$ showed high catalytic performance in the first use, with yields of $46 \%$ after $1 \mathrm{~h}$ and $75 \%$ after $4 \mathrm{~h}$. Initial TOF (mmol converted per mmol of catalyst per second) was calculated using conversion after $1 \mathrm{~h}$ and considering the total sulfur content (by elemental analysis) as $\mathrm{SO}_{3} \mathrm{H}$ groups. The TOF value $\left(17.4 \times 10^{-3}\right.$ $\mathrm{s}^{-1}$, Table 2) is higher than values reported for sulfonated carbons in analogue reactions, (e. g. $1.6 \times 10^{-3} \mathrm{~s}^{-1}$ with sulfonated mesoporous carbon [15] or $5.4 \times 10^{-3} \mathrm{~s}^{-1}$ with sulfonated incompletely carbonized glucose [11] in esterification of oleic acid with methanol, Table 2) and similar to values obtained in esterification of lower acids $\left(16.7 \times 10^{-3} \mathrm{~s}^{-1}\right.$ with sulfonated partially carbonized cellulose in esterification of acetic acid with ethanol [13], Table 2). However, a significant drop in the catalytic activity upon reuse was observed 
(Figure 4), with an initial TOF of $6.4 \times 10^{-3}$ (Table 3). The deactivation behavior of sulfonated carbons has been described with different degree of detail in some cases $[12,15,18,33]$, and also with other solid sulfonic acids [36]. On the contrary, some authors describe a complete stability of the sulfonated carbons in the same type of reactions $[10,11]$. Degradation of the catalyst might be due to a prolonged period of stirring under reaction conditions, and in a second test the reaction was stopped after only $6 \mathrm{~h}$, reaching nearly $90 \%$ yield. In such case the drop in catalytic activity (Figure 4) was less pronounced $\left(\mathrm{TOF}=13.8 \times 10^{-3}\right.$, Table 3 ), showing the role of contact time between catalyst and reaction medium in the deactivation process.

Catalytic activity depends on the alcohol used in the esterification reaction, in the order methanol $\left(\mathrm{TOF}=17.4 \times 10^{-3} \mathrm{~s}^{-1}\right)>$ ethanol $\left(\mathrm{TOF}=10.6 \times 10^{-3} \mathrm{~s}^{-1}\right)>>$ isopropanol $\left(\mathrm{TOF}=1.5 \times 10^{-3} \mathrm{~s}^{-1}\right)$, in agreement with the slower reaction with a sterically more hindered secondary alcohol. In all cases deactivation occurs, irrespective of the alcohol used.

\subsection{Deactivation studies}

The deactivation of sulfonated carbons had been ascribed, at least in part, to extraction of soluble sulfonated material into the liquid phase, both in the case of carbon prepared by pyrolysis of glucose [33] and in hydrothermal carbons prepared from $p$ toluenesulfonic acid/glucose/resorcinol mixtures [14]. The sulfur analysis of the recovered catalyst (Table 1) seems to confirm this hypothesis, although a loss of $18 \%$ in sulfur content cannot account for a loss of $65 \%$ in activity (Table 3 ). To assess the effect of leaching on deactivation, $\mathrm{HC}-\mathrm{SO}_{3} \mathrm{H}$ was pretreated with different solvents under reflux and the solid was tested after hot filtration to prevent deposition of the leached material. Figure 
5 gathers the ester yield vs time graphs for pretreated catalysts in comparison with the untreated one (dashed lines) in successive cycles.

Properties of the treated solids, including sulfur content (Table 1) and catalytic activity (Table 3 and Figure 5), strongly depend on the solvent used in the pretreatment. Treatment with toluene under reflux for $72 \mathrm{~h}$ led to a solid with slightly lower sulfur content $\left(0.49 \mathrm{mmol} \mathrm{g}^{-1}\right)$ but the same catalytic activity as the fresh catalyst. The low solubility of the highly oxygenated species of the hydrothermal carbon may account for this behavior. On the contrary, these species should be more soluble in acetone, and the analysis of the solid treated with acetone under reflux for $72 \mathrm{~h}\left(0.42 \mathrm{mmol} \mathrm{g}^{-1}\right)$ agrees with this point. In spite of the slightly higher degree of leaching compared with the analysis of the used catalyst $\left(0.45 \mathrm{mmol} \mathrm{g}^{-1}\right)$, the decrease in activity is only minor, considering the weight of catalyst (Figure 5A) and even the sites on the solid show slightly higher activity (TOF, Table 3). Furthermore, the acetone extract was evaporated under vacuum and the residue was used as catalyst in another esterification reaction, with very low catalytic activity (Figure 5A), accounting for the difference in yield observed between the fresh catalyst and the treated one.

The situation is completely different when using an alcohol as solvent for treatment. Treatment with 1-propanol under reflux for $72 \mathrm{~h}$ produces an important degree of sulfur leaching, reducing its content $\left(0.32 \mathrm{mmol} \mathrm{g}^{-1}\right)$ to less than $60 \%$ of the initial amount. Consequently, the activity of the solid is significantly reduced (Figure 5A) but the activity per site remains high (TOF $13.6 \times 10^{-3} \mathrm{~s}^{-1}$ compared to $17.4 \times 10^{-3} \mathrm{~s}^{-1}$ of the fresh catalyst). In the case of methanol, treatment under reflux was carried out only for $24 \mathrm{~h}$ (reaction conditions). The loss of sulfur is analogous to that observed under reaction conditions (Table 1) but deactivation is much higher (Figure 5A), leading to the lowest TOF among 
the pretreated and recovered catalysts $\left(2.7 \times 10^{-3} \mathrm{~s}^{-1}\right){ }^{*}$ similar to the activity of the untreated catalyst in the third cycle (Figure 5A and Table 3). On the other hand, the activity of the liquid extract obtained in the pretreatment was also tested to detect leaching of acidic species. The methanol extract showed the same low activity as that observed in the case of the extract in acetone (Figure 5A). Moreover this activity does not account for the drop in catalytic activity of the solid, demonstrating the existence of at least a second and more important deactivation mechanism based on the presence of methanol, or alcohols in general taking into account the deactivation in the esterification with ethanol or isopropanol. In fact, as deactivation is produced by simple pretreatment with alcohol, it cannot be ascribed to the presence of adsorbed products or by-products responsible for pore or acid sites blocking, as proposed for some sulfonic catalysts [36,37].

Recovery of pretreated catalysts (Figure 5B) shows that catalytic behavior is quite similar in all cases, with a very significant drop in catalytic activity, analogous to that observed in the fresh catalyst. Moreover, sulfur analysis of the recovered catalyst pretreated in toluene (Table 1) shows a drop in sulfur content, from 0.49 to $0.40 \mathrm{mmol} \mathrm{g}^{-1}$, similar to that observed in the use of fresh catalyst, from 0.55 to $0.45 \mathrm{mmol} \mathrm{g}^{-1}$. In view of all these results, the partially deactivated catalysts were analyzed by solid state NMR.

\subsection{NMR study of deactivated catalysts}

Pretreatment with toluene did not produce any significant modification of the ${ }^{13} \mathrm{C}$ CP-MAS-NMR spectrum of $\mathrm{HC}-\mathrm{SO}_{3} \mathrm{H}$ with respect to the freshly prepared catalyst (Figure 6 ), in agreement with the same catalytic activity observed. On the contrary, the solid pretreated with methanol, as well as the catalyst recovered after esterification (not shown),

\footnotetext{
* This seems to be the limit for deactivation with alcohol, as the pretreatment with methanol under reflux for $96 \mathrm{~h}$ leads to the same catalytic activity.
} 
presents a prominent signal at $52 \mathrm{ppm}$. This signal is compatible with a methoxy $\left(-\mathrm{OCH}_{3}\right)$ group, with a chemical shift between those of methanol (49 ppm) and methyl ptoluenesulfonate $(56 \mathrm{ppm})$. The line width $(\mathrm{fwhm}=620 \mathrm{~Hz})$ seems to indicate a lack of mobility, together with a possible distribution of different types of sites. Both effects may be due either to a strong physisorption of molecular methanol by formation of hydrogen bonds with the highly oxygenated structure of the hydrothermal carbon or to chemical reaction of methanol with some sulfonic groups leading to surface methyl sulfonates. Some authors have proposed this possibility in the deactivation of mesoporous silicas modified with sulfonic groups [38,39], but without experimental evidences.

Given that 1-propanol is also able to partially deactivate the catalyst, it was used to test the presence of weakly physisorbed alcohol, taking advantage of its lower volatility. In addition to the pretreatment under reflux, the catalyst was also treated with 1-propanol at room temperature for a shorter time $(5 \mathrm{~h})$ and the ${ }^{13} \mathrm{C}-\mathrm{CP}-\mathrm{MAS}-\mathrm{NMR}$ spectra of both samples were recorded (Figure 7). The spectrum of the sample pretreated under reflux shows the three signals typical for 1-propanol at $67.7,21.3$, and $8.7 \mathrm{ppm}$, but with highly restricted mobility as shown by the line widths, 460,320 and $400 \mathrm{~Hz}$, respectively. In the case of the sample pretreated at room temperature a double set of signals appears, with the minor ones at the same chemical shifts (only visible those corresponding to $\mathrm{C} 1$ and $\mathrm{C} 2$ ) with similar line width, and the major ones with line widths in the 120-170 Hz range appearing at $63.6,25.5$ and $9.8 \mathrm{ppm}$. The signals can be then tentatively assigned to chemically bound propyl groups, favorably formed at high temperature, and more mobile strongly adsorbed (hydrogen bonded) propanol molecules. In this case, as the solid was not washed or dried under vacuum, weakly physisorbed propanol should remain on the solid, but the high mobility of those molecules make them not detectable by CP technique due to 
the fast relaxation. In order to confirm this point, the direct polarization ${ }^{13} \mathrm{C}\left\{{ }^{1} \mathrm{H}\right\}$-MASNMR spectrum was also registered (Figure 7) showing the very narrow signals corresponding to liquid propanol at $66.2,28.1$ and $12.5 \mathrm{ppm}$.

A further confirmation of this point was obtained by ${ }^{1}$ H-MAS-NMR spectroscopy (Figure 8). The spectrum of the sample pretreated under reflux shows only very broad signals in agreement with the strong H-H dipolar coupling due to the lack of mobility of the surface species. In the case of the sample pretreated at room temperature, the presence of highly mobile liquid propanol is clearly shown by the very narrow signals, including that of hydroxyl group at $5 \mathrm{ppm}$.

In order to confirm the presence of chemically bound propyl groups, solids pretreated with 1-propanol were thoroughly washed with acetone and the ${ }^{13} \mathrm{C}-\mathrm{CP}-\mathrm{MAS}$ NMR spectra were registered after drying under vacuum (Figure 9). As can be seen the spectrum of the sample pretreated under reflux remains unchanged, showing that chemically bound propyl groups are mainly formed at high temperature. On the other hand, the spectrum of the sample pretreated at room temperature keeps only small signals at the same chemical shifts, whereas the second set of more intense signals has disappeared, confirming that it corresponded to strongly physisorbed alcohol, as well as those of the liquid propanol detectable by direct polarization (not shown). In agreement with the very low amount of chemically bound propyl groups, the solid pretreated at room temperature shows the same activity per site than the fresh catalyst (Table 2), and the drop in activity per weight is mainly due to leaching.

An additional proof for the effect of the reaction of sulfonated carbon with alcohol on deactivation is the correlation between the intensity of the alkyl signal in the CP-MASNMR spectrum and the TOF of catalysts pretreated under different conditions. Two 
samples of $\mathrm{HC}_{-} \mathrm{SO}_{3} \mathrm{H}$ were pretreated with methanol under reflux for 2 and $6 \mathrm{~h}$, in addition to the sample pretreated for $96 \mathrm{~h}$. The band corresponding to $\mathrm{MeO}$ groups was integrated and normalized with respect to the broad band of the HC structure at 200-80 ppm, and the initial TOF of the esterification reaction obtained with those three pretreated catalysts and the freshly prepared one was represented $v$ s the normalized integral. ${ }^{\dagger}$ As can be seen in Figure 10 there exist a clear correlation between catalytic activity and the presence of the methoxy groups in the solid, showing that they are formed by covalent bonding at expenses of the acid sites.

The NMR study, together with the deactivation results, points to a general picture of the interaction between $\mathrm{HC}-\mathrm{SO}_{3} \mathrm{H}$ with alcohols (Scheme 1) in which at room temperature the formation of hydrogen bonds between the alcohol and the different protic groups of the material (sulfonic and carboxylic acids, hydroxyls of alcohols and phenols) is favored, whereas under heating those species evolve to alkyl esters (sulfonic and carboxylic) or alkyl ethers. Reactivity of the different groups in the solid will be different, also depending on the nature of the alcohol, with methanol being the most reactive and hence the most deactivating for the solid acid. Experiments are currently in progress to demonstrate the generality of this effect on different solid acids.

\footnotetext{
${ }^{\dagger}$ The $\mathrm{MeO}$ band overlaps with that corresponding to residual aliphatic carbons in the catalyst. Hence the value of the integral was not zero in the case of the freshly prepared catalyst.
} 


\section{Conclusions}

The sulfonated hydrothermal carbons are highly active for esterification of palmitic acid with different alcohols (methanol, ethanol, 1-propanol), but the catalysts suffer an important deactivation upon recovery. Leaching of sulfonated species has only a minor role in this deactivation, as shown by pretreatment in aprotic solvents. On the contrary, the main deactivation mechanism is produced by simple treatment with alcohol. This deactivation is highly dependent on the nature of the alcohol, with methanol as the most efficient for deactivation. Solid state NMR shows the presence of bound alcohol on the catalyst, strongly physisorbed in the case of solid pretreated at room temperature and chemically bound in the case of solid pretreated under reflux. The formation of sulfonate esters by reaction of the sulfonic groups in the solid with the alcohol at high temperature explains the strongly deactivating effect of alcohol.

\section{Acknowledgements}

This work was made possible by the financial support of Aragón regional government (project PI050/09), the Spanish Ministerio de Ciencia e Innovación (projects MAT 200802365, and CTQ2011-28124) and the European Commission (Grant agreement No. 226347).

\section{References}

[1] P. T. Anastas, J. C. Warner, Green Chemistry Theory and Practice; Oxford University Press, New York, 1998.

[2] J. H. Clark, Acc. Chem. Res. 35 (2002) 791.

[3] T. Okuhara, Chem. Rev. 102 (2002) 3641. 
[4] E. Lotero, Y. Liu, D. E. López, K. Suwannakarn, D. A. Bruce, J. G. Goodwin Jr., Ind. Eng. Chem. Res. 44 (2005) 5353.

[5] M. Di Serio, R. Tesser, L. Pengmei, E. Santacesaria, Energy Fuels 22 (2008) 207.

[6] K. Suwannakarn, E. Lotero, K. Ngaosuwan, J. G. Goodwin Jr., Ind. Eng. Chem. Res. 48 (2009) 2810.

[7] V. L. Budarin, J. H. Clark, R. Luque, D. J. Macquarrie, Chem. Commun. (2007) 634.

[8] M. Hara, T. Yoshida, A. Takagaki, T. Takata, J. N. Kondo, S. Hayashi, K. Domen, Angew. Chem. Int. Ed. 43 (2004) 2955.

[9] M. Okamura, A. Takagaki, M. Toda, J. N. Kondo, K. Domen, T. Tatsumi, M. Hara, S. Hayashi, Chem. Mater. 18 (2006) 3039.

[10] A. Takagaki, M. Toda, M. Okamura, J. N. Kondo, S. Hayashi, K. Domen, M. Hara, Catal. Today $116(2006) 157$.

[11]M.-H. Zong, Z.-Q. Duan, W.-Y. Lou, T. J. Smith, H. Wu, Green Chem. 9 (2007) 434.

[12]X. Mo, E. Lotero, C. Lu, Y. Liu, J. G. Goodwin, Catal. Lett. 123 (2008) 1.

[13]K. Fukuhara, K. Nakajima, M. Kitano, H. Kato, S. Hayashi, M. Hara, ChemSusChem 4 (2011) 778 .

[14]W. Zhang, H. Tao, B. Zhang, J. Ren, G. Lu, Y. Wang, Carbon 49 (2011) 1811.

[15]L. Peng, A. Philippaerts, X. Ke, J. Van Noyen, F. De Clippel, G. Van Tendeloo, P. A. Jacobs, B. F. Sels, Catal. Today 150 (2010) 140.

[16]B. Hu, K. Wang, L. H. Wu, S. H. Yu, M. Antonietti, M. M. Titirici, Adv. Mater. 22 (2010) 813.

[17]M. Sevilla, A. Fuertes, Chem. Eur. J. 15 (2009) 4195.

[18]J. A. Maciá-Agulló, M. Sevilla, M. A. Diez, A. B. Fuertes, ChemSusChem 3 (2010) 1352. 
[19]X. Liang, M. Zeng, C. Qi, Carbon 48 (2010) 1844.

[20] M.-M. Titirici, A. Thomas, M. Antonietti, J. Mater. Chem. 17 (2007) 3412.

[21]R. J. White, K. Tauer, M. Antonietti, M.-M. Titirici, J. Am. Chem. Soc. 132 (2010) 17360.

[22]X. Sun, Y. Li, J. Colloid Interf. Sci. 291 (2005) 7.

[23]Y. Fang, D. Gu, Y. Zou, Z. Wu, F. Li, R. Che, Y. Deng, B. Tu, D. Zhao, Angew. Chem. Int. Ed. 49 (2010) 7987.

[24] M. Li, W. Li, S. Liu, Carbohydrate Res. 346 (2011) 999.

[25] S. Ikeda, K. Tachi, Y. H. Ng, Y. Ikoma, T. Sakata, H. Mori, T. Harada, M. Matsumura, Chem. Mater. 19 (2007) 4335.

[26]Z. Wen, Q. Wang, Q. Zhang, J. Li, Electrochem. Commun. 9 (2007) 1867.

[27]X. Sun, Y. Li, J. Colloid Interf. Sci. 291 (2005) 7.

[28]Y. Yan, H. Yang, F. Zhang, B. Tu, D. Zhao, Small 2 (2006) 517.

[29]Z. Wen, Q. Wang, J. Li, Adv. Funct. Mater. 18 (2008) 959.

[30]L. Roldán, I. Santos, S. Armenise, J. M. Fraile, E. García-Bordejé, Carbon 50 (2012) 1363.

[31]Deactivation and testing of hydrocarbon-processing catalysts, ACS Symposium Series, No 634; P. O'Connor, T. Takatsuka, G. L. Woolery, Eds.; American Chemical Society, 1996.

[32] Deactivation and poisoning of catalysts; J. Oudar, H. Wise, Eds.; Dekker, 1985.

[33]X. Mo, D. E. López, K. Suwannakarn, Y. Liu, E. Lotero, J. G. Goodwin Jr., C. Lu, J. Catal. 254 (2008) 332.

[34]X. Tian, L. L. Zhang, P. Bai, X. S. Zhao, Catal. Today 166 (2011) 53.

[35]K. Suwannakarn, E. Lotero, J. G. Goodwin Jr., C. Lu, J. Catal. 255 (2008) 279. 
[36] Y. Liu, E. Lotero, J. G. Goodwin Jr., J. Catal. 243 (2006) 221.

[37] A. C. Alba-Rubio, F. Vila, D. Martín Alonso, M. Ojeda, R. Mariscal, M. López Granados, Appl. Catal. B: Environm. 95 (2010) 279.

[38] J. A. Melero, L. F. Bautista, G. Morales, J. Iglesias, D. Briones, Energy Fuels 23 (2009) 539.

[39] J. A. Melero, L. F. Bautista, G. Morales, J. Iglesias, R. Sánchez-Vázquez, Chem. Eng. J. $161(2010) 323$.

[40] M.-M. Titirici, M. Antonietti, N. Baccile, Green Chem. 10 (2008) 1204.

[41]N. Baccile, G. Laurent, F. Babonneau, F. Fayon, M.-M. Titirici, M. Antonietti, J. Phys. Chem. C 113 (2009) 9644. 
Table 1. Chemical composition $\left(\mathrm{CH}_{\mathrm{x}} \mathrm{O}_{\mathrm{y}} \mathrm{S}_{\mathrm{z}}\right)$ and sulfur content of hydrothermal carbons.

\begin{tabular}{|c|c|c|c|c|c|}
\hline Sample & Treatment & $\mathrm{x}$ & $\mathrm{y}$ & $\mathrm{z}$ & $\mathrm{S}\left(\mathrm{mmol} \mathrm{g}^{-1}\right)$ \\
\hline $\mathrm{HC}$ & - & 0.796 & 0.304 & 0.000 & 0.00 \\
\hline $\mathrm{HC}-\mathrm{SO}_{3} \mathrm{H}$ & - & 0.466 & 0.528 & 0.012 & 0.55 \\
\hline $\mathrm{HC}-\mathrm{SO}_{3} \mathrm{H}$ & Esterification $^{\mathrm{a}}$ & 0.563 & 0.492 & 0.010 & 0.45 \\
\hline $\mathrm{HC}-\mathrm{SO}_{3} \mathrm{H}$ & Esterifications $(2)^{\mathrm{a}}$ & 0.816 & - & 0.008 & 0.42 \\
\hline $\mathrm{HC}-\mathrm{SO}_{3} \mathrm{H}$ & Esterifications $(3)^{\mathrm{a}}$ & 0.497 & - & 0.009 & 0.41 \\
\hline $\mathrm{HC}-\mathrm{SO}_{3} \mathrm{H}$ & $\mathrm{MeOH}(24 \mathrm{~h})^{\mathrm{b}}$ & 0.597 & 0.533 & 0.010 & 0.46 \\
\hline $\mathrm{HC}-\mathrm{SO}_{3} \mathrm{H}$ & Toluene $^{b}$ & 0.592 & 0.435 & 0.010 & 0.49 \\
\hline $\mathrm{HC}-\mathrm{SO}_{3} \mathrm{H}$ & Toluene $^{\mathrm{b}}+$ esterification $^{\mathrm{a}}$ & 0.633 & 0.427 & 0.008 & 0.40 \\
\hline $\mathrm{HC}-\mathrm{SO}_{3} \mathrm{H}$ & Acetone $^{\mathrm{b}}$ & 0.575 & 0.439 & 0.008 & 0.42 \\
\hline $\mathrm{HC}-\mathrm{SO}_{3} \mathrm{H}$ & Acetone $^{\mathrm{b}}+$ esterification $^{\mathrm{a}}$ & 0.518 & - & 0.007 & 0.36 \\
\hline $\mathrm{HC}-\mathrm{SO}_{3} \mathrm{H}$ & 1-Propanol ${ }^{\mathrm{b}}$ & 0.667 & 0.421 & 0.007 & 0.32 \\
\hline $\mathrm{HC}-\mathrm{SO}_{3} \mathrm{H}$ & 1-Propanol ${ }^{\mathrm{b}}+$ esterification $^{\mathrm{a}}$ & 0.546 & - & 0.006 & 0.32 \\
\hline $\mathrm{HC}-\mathrm{SO}_{3} \mathrm{H}$ & 1-Propanol ${ }^{c}$ & 0.606 & 0.508 & 0.008 & 0.36 \\
\hline $\mathrm{HC}-\mathrm{SO}_{3} \mathrm{H}$ & 1-Propanol ${ }^{\mathrm{c}}+$ esterification $^{\mathrm{a}}$ & 0.484 & - & 0.007 & 0.35 \\
\hline
\end{tabular}

${ }^{a}$ Catalyst used in an esterification reaction of palmitic acid with methanol under reflux for $24 \mathrm{~h}$. Successive recycles in parenthesis. ${ }^{\mathrm{b}}$ Treatment with the solvent under reflux for $72 \mathrm{~h}$ (unless otherwise stated). ${ }^{\mathrm{c}}$ Treatment at r. t. for $5 \mathrm{~h}$. 
2 Table 2. Conditions and catalytic activity in esterification reactions of sugar-derived sulfonated carbons.

\begin{tabular}{|c|c|c|c|c|c|c|c|c|}
\hline Ref. & Acid & Alcohol & $\begin{array}{c}\text { Catalyst } \\
\text { (functionalization) }\end{array}$ & $\begin{array}{c}\text { Acid/catalyst } \\
\text { ratio }\end{array}$ & $\mathrm{T}\left({ }^{\circ} \mathrm{C}\right)$ & $\mathrm{t}(\mathrm{h})$ & $\begin{array}{l}\text { Yield } \\
(\%)\end{array}$ & $\begin{array}{l}\text { initial TOF } \\
\qquad\left(\mathrm{s}^{-1}\right)\end{array}$ \\
\hline 11 & $\begin{array}{c}\text { Oleic } \\
(10 \mathrm{mmol})\end{array}$ & $\mathrm{MeOH}$ & $\begin{array}{c}140 \mathrm{mg} \\
(4.7 \% \mathrm{~S})\end{array}$ & 48.5 & reflux & 0.5 & 20 & $5.4 \times 10^{-3}$ \\
\hline 13 & $\begin{array}{c}\text { Acetic } \\
(100 \mathrm{mmol})\end{array}$ & $\mathrm{EtOH}$ & $\begin{array}{c}200 \mathrm{mg} \\
(1.8 \mathrm{mmol} \mathrm{S} / \mathrm{g})\end{array}$ & 277.8 & 70 & - & - & $16.7 \times 10^{-3}$ \\
\hline 15 & $\begin{array}{c}\text { Oleic } \\
(25 \mathrm{mmol})\end{array}$ & $\mathrm{MeOH}$ & $\begin{array}{c}430 \mathrm{mg} \\
\left(=1 \mathrm{mmol} \mathrm{H}^{+}\right)\end{array}$ & 25.0 & reflux & 1 & 23 & $1.6 \times 10^{-3}$ \\
\hline this work & $\begin{array}{l}\text { Palmitic } \\
(7.5 \mathrm{mmol})\end{array}$ & $\mathrm{MeOH}$ & $\begin{array}{c}100 \mathrm{mg} \\
(1.76 \% \mathrm{~S})\end{array}$ & 136.4 & reflux & 1 & 46 & $17.4 \times 10^{-3}$ \\
\hline
\end{tabular}

3 
Table 3. Catalytic activity of $\mathrm{HC}-\mathrm{SO}_{3} \mathrm{H}$ in esterification of palmitic acid with methanol. ${ }^{\mathrm{a}}$

\begin{tabular}{|c|c|}
\hline Pretreatment & initial TOF $\left(\mathrm{s}^{-1}\right)^{\mathrm{b}}$ \\
\hline- & $17.4 \times 10^{-3}$ \\
\hline $\operatorname{used}^{c}(24 h)$ & $6.4 \times 10^{-3}$ \\
\hline $\operatorname{used}^{\mathrm{c}}(6 \mathrm{~h})$ & $13.8 \times 10^{-3}$ \\
\hline used twice $^{c}(24 \mathrm{~h})$ & $3.0 \times 10^{-3}$ \\
\hline $\mathrm{MeOH}(24 \mathrm{~h})^{\mathrm{d}}$ & $2.7 \times 10^{-3}$ \\
\hline Toluene $^{\mathrm{d}}$ & $18.8 \times 10^{-3}$ \\
\hline Toluene $^{\mathrm{d}}+\operatorname{used}^{\mathrm{c}}(24 \mathrm{~h})$ & $4.2 \times 10^{-3}$ \\
\hline Acetone $^{\mathrm{d}}$ & $20.4 \times 10^{-3}$ \\
\hline Acetone $^{\mathrm{d}}+$ used $^{\mathrm{c}}(24 \mathrm{~h})$ & $10.4 \times 10^{-3}$ \\
\hline 1-Propanol ${ }^{\mathrm{d}}$ & $13.6 \times 10^{-3}$ \\
\hline $1-$ Propanol $^{\mathrm{d}}+$ used $^{\mathrm{c}}(24 \mathrm{~h})$ & $5.9 \times 10^{-3}$ \\
\hline 1-Propanol ${ }^{\mathrm{e}}$ & $17.5 \times 10^{-3}$ \\
\hline 1-Propanol ${ }^{\mathrm{e}}+$ used $^{\mathrm{c}}(24 \mathrm{~h})$ & $6.6 \times 10^{-3}$ \\
\hline
\end{tabular}

${ }^{\mathrm{a}}$ Under reflux for $24 \mathrm{~h} .{ }^{\mathrm{b}}$ Calculated as: (initial mmol of palmitic acid $\times$ conversion after $1 \mathrm{~h} / 100) /($ mass of catalyst $\times S$ content $\times$ 3600). ${ }^{c}$ Catalyst used in an esterification for the specified reaction time. ${ }^{\mathrm{d}}$ Treatment with the solvent under reflux for $72 \mathrm{~h}$ (unless otherwise stated). ${ }^{\mathrm{e}}$ Treatment at r. t. for $5 \mathrm{~h}$. 


\section{Figure Captions}

Figure 1. SEM image of HC.

Figure 2. IR spectra of $\mathrm{HC}$ (bottom) and $\mathrm{HC}_{-} \mathrm{SO}_{3} \mathrm{H}$ (top).

Figure $3 .{ }^{13} \mathrm{C}-\mathrm{CP}-\mathrm{MAS}-\mathrm{NMR}$ spectra of $\mathrm{HC}$ (bottom) and $\mathrm{HC}-\mathrm{SO}_{3} \mathrm{H}$ (top).

Figure 4. Yield of methyl palmitate: (ם) $\mathrm{HC}-\mathrm{SO}_{3} \mathrm{H}$, reaction stopped after 24 h. ( $\left.\mathbf{\Delta}\right) \mathrm{HC}$ $\mathrm{SO}_{3} \mathrm{H}$, reaction stopped after $6 \mathrm{~h},(\diamond)$ blank $(\mathrm{HC})$. Solid line: first use. Dashed line: second use.

Figure 5. A) Yield of methyl palmitate after pretreatment of $\mathrm{HC}-\mathrm{SO}_{3} \mathrm{H}$ in refluxing solvents: $(\times)$ toluene, $(\boldsymbol{\Delta})$ acetone, $(\diamond)$ propanol, $(\boldsymbol{\square})$ methanol. Dotted line: activity of the acetone extract (see text). Dashed lines: results with fresh untreated catalyst in the successive cycles. B) Second use of treated catalysts.

Figure $6 .{ }^{13} \mathrm{C}-\mathrm{CP}-\mathrm{MAS}-\mathrm{NMR}$ spectra of as-prepared $\mathrm{HC}-\mathrm{SO}_{3} \mathrm{H}$ (bottom) and treated with toluene (middle) or methanol (top) under reflux.

Figure 7. ${ }^{13} \mathrm{C}-\mathrm{CP}-\mathrm{MAS}-\mathrm{NMR}$ spectra of $\mathrm{HC}-\mathrm{SO}_{3} \mathrm{H}$ treated with 1-propanol under reflux (top) and at rt (middle). Bottom: direct polarization spectrum of the sample treated at $\mathrm{rt}$.

Figure 8. ${ }^{1} \mathrm{H}-\mathrm{MAS}-\mathrm{NMR}$ spectra of $\mathrm{HC}-\mathrm{SO}_{3} \mathrm{H}$ treated with 1-propanol under reflux (top) and at rt (bottom).

Figure 9. ${ }^{13} \mathrm{C}-\mathrm{CP}-\mathrm{MAS}-\mathrm{NMR}$ spectra of $\mathrm{HC}-\mathrm{SO}_{3} \mathrm{H}$ pretreated with 1-propanol and then washed with acetone: treatment under reflux (top) and at rt (bottom).

Figure 10. Initial TOF $\left(\mathrm{h}^{-1}\right)$ in esterification of palmitic acid with methanol vs normalized integral of the methoxy band in CP-MAS-NMR of the pretreated catalyst in methanol for different times. 
